\title{
Formação de professoras para avaliar crianças com transtorno do espectro autista
}

\section{Teacher training to evaluate children with autism spectrum disorder}

\author{
Lívia da Conceição Costa Zaqueu ${ }^{1 *}$, Michele Maria de Oliveira ${ }^{1 *}$, Francisca Morais da \\ Silveira ${ }^{1}$, Claudia Regina Maciel Azevedo ${ }^{2}$, Arteane Gomes de Sousa Setúbal ${ }^{2}$, Ginia Kenia \\ Machado Maia ${ }^{1}$, Margareth Santos Fonseca ${ }^{2}$
}

\begin{abstract}
RESUMO
O objetivo deste artigo foi realizar a formação de professores para avaliar o desenvolvimento infantil de crianças com Transtorno do Espectro Autista com base em dois instrumentos para subsidiar intervenções educacionais para crianças de creches públicas do município de São Luís - MA. Foi feita a formação das professoras em dois instrumentos: Skill Growing Test, que avalia áreas crescentes do desenvolvimento infantil, e o Perfil Psicoeducacional Revisado PEP-R, que avalia sete áreas do desenvolvimento. Foi aplicado um questionário com seis perguntas para duas professoras, a formação representou uma etapa mista com nove encontros online e presencial. A formação corroborou com a fundamentação teórica para atuar com crianças com TEA e oferecer subsídios científicos para avaliar e orientar as famílias na interação com filhos no ambiente doméstico, ampliando as intervenções que realizadas nas atividades exercidas no Atendimento Educacional Especializado-AEE, mostrando-se essencial para ampliar as possibilidades de intervenção precoce na infância e conduzir estudos no contexto de creches públicas no município de São Luís produzindo boas evidências sobre a formação das professoras de crianças com TEA e suas famílias.
\end{abstract}

Palavras-chave: Formação; Transtorno do espectro autista; Crianças; Intervenção precoce; Pandemia Covid-19.

\begin{abstract}
The objective of this article was to train teachers to assess the child development of children with Autism Spectrum Disorder based on two instruments to support educational interventions for children in public daycare centers in the city of São Luís - MA. Teachers were trained in two instruments: the Skill Growing Test which assesses growing areas of child development and the Revised Psychoeducational Profile PEP$\mathrm{R}$ which assesses 7 areas of development. A questionnaire with six questions was applied to two teachers, the training represented a mixed stage with nine online and face-to-face meetings. The training corroborated with the theoretical foundation to work with children with ASD and offer scientific subsidies to evaluate and guide families in the interaction with children in the domestic environment, expanding the interventions carried out in the activities carried out in the Specialized Educational Service-SES, proving to be essential to expand the possibilities of early intervention in childhood and conduct studies in the context of public daycare centers in the city of São Luís, producing good evidence on the training of teachers of children with ASD and their families.
\end{abstract}

Keywords: Formation; Autistic Spectrum Disorder; Children; Early intervention; Pandemic Covid-19.

\footnotetext{
${ }^{1}$ Universidade Federal do MaranhãoB

${ }^{2}$ Secretaria Municipal de Educação de São Luís

E-mail: conceicaozaqueu@gmail.com
} 


\section{INTRODUÇÃO}

O Transtorno do Espectro Autista - TEA é definido no Manual de Classificação Estatística dos Transtornos Mentais - DSM-5 (APA, 2014), como um transtorno do neurodesenvolvimento que afetam em diferentes níveis as habilidades de socialização, dificuldade de comunicação, interação social que vai desde a comunicação verbal e não verbal a um engajamento de repertórios comportamentais com interesses restritos e movimentos de padrão repetitivo (APA, 2014).

O TEA se caracteriza como uma categoria de transtornos com importante impacto social. Neste sentido, equipes de educação/saúde devem estar preparadas para verificar criteriosamente a linha de base de habilidades de crianças diagnosticadas, particularmente no que se refere aos perfis de desenvolvimento, cognição, comunicação, sensorialidade, motricidade e comportamento (ZAQUEU et al., 2015; BRASIL; SAULNIER et al., 2011). Sendo assim, crianças diagnosticadas com TEA podem ter grandes dificuldades quando suas rotinas mudam, e isso poderá afetar o bem-estar de suas famílias.

A Política Nacional de Proteção dos Direitos da Pessoa com Transtorno do Espectro Autista instituída no Brasil em 2012, por meio da Lei ${ }^{0} 12.764 / 2012$, estabelece diretrizes gerais e vem reconhecer a pessoa com TEA como tendo uma deficiência para fins de aquisição de direitos. Neste aspecto, esta política garante aos estudantes com TEA matriculados na sala comum do ensino regular a oferta do atendimento educacional especializado (BRASIL, 2012). Além disso, ainda sinaliza para o incentivo a formação de professores especializados, assim como orientação às famílias e o estímulo à pesquisa científica na área.

O Atendimento Educacional Especializado - AEE foi pensado na Lei de Diretrizes e Bases da Educação Nacional - LDB (BRASIL, 1996) para ser ofertado sempre que necessário, visto crianças com diferentes deficiências apresentarem limitações no aprendizado necessitado desse atendimento junto à educação comum regular. Assim, a intervenção educacional para estudantes com TEA nas escolas públicas brasileiras tem sido efetivada por meio da matrícula na sala comum do ensino regular e também da matrícula no serviço de Atendimento Educacional Especializado -AEE cujo serviço acontece na Sala de Recursos Multifuncionais - SRM, geralmente oferecido na 
mesma escola, no contraturno com função de complementar ou suplementar (BRASIL, 2008).

Em geral, os professores que atuam no AEE precisam desenvolver a sua prática pedagógica em articulação com os professores da sala comum do ensino regular, sendo esse apoio necessário no atendimento às especificidades desses estudantes. Por isso, conhecer instrumentos de avaliação das competências e habilidades crescentes das crianças em diferentes áreas do desenvolvimento é essencial no direcionamento do planejamento dos professores frente as respostas educativas dos estudantes.

A infância é considerada uma fase adequada para investigação e constitui-se como uma ação preventiva que compreende atividades que vão desde a identificação que se dá por meio de uma avaliação criteriosa com instrumentos padronizados até o encaminhamento para programas de intervenção precoce ou essencial (ORGANIZAÇÃO PAN-AMERICANA DE SAÚDE, 2005). Existe também a necessidade de se trabalhar com professores, visto, serem construtores de conhecimento e estarem diretamente ligados aos estudantes promovendo ações pedagógicas que influenciam no desenvolvimento das distintas áreas, estimulando suas potencialidades e, por conseguinte, trabalhando os déficits que os alunos possuem.

A literatura tem avançado bastante em estudos focalizando na criança com TEA, atenção as famílias e/ou investigação sobre algumas práticas pedagógicas, mas poucos estudos no Brasil têm trabalhado com estratégias de formação para professores para avaliar crianças diagnosticadas com esse transtorno matriculadas em creches públicas com instrumentos científicos. Diante disso, constatamos que no estado do Maranhão ainda há necessidade de estudos que venham ampliar conhecimentos sobre o desenvolvimento de crianças com TEA no contexto da pandemia do SARS-CoV-2. Por este motivo, este artigo corrobora com a aquisição de conhecimentos de professoras da educação especial e inclusiva na educação básica que atuam com crianças diagnosticadas com Transtorno do Espectro do Autista - TEA em creches públicas do município de São Luís/MA em tempos de pandemia do SARS-CoV-2 (Síndrome respiratória aguda grave coronavírus). Acredita-se que profissionais da educação devem ser orientados para avaliar o desenvolvimento de crianças com TEA no contexto de creches públicas com o propósito de aplicarem intervenções especificas de acordo com as áreas afetadas e isso, poderá impactar positivamente no desenvolvimento dessas crianças e de suas famílias. 
Assim, o objetivo deste artigo foi realizar a formação de professoras da educação infantil de duas creches públicas para avaliar o desenvolvimento de crianças com Transtorno do Espectro Autista com base em dois instrumentos avaliativos a fim de fornecer conhecimentos que irão embasar intervenções educacionais frente às necessidades dessas crianças no contexto da Pandemia da COVID 19 no município de São Luís - MA.

\section{A avaliação do desenvolvimento infantil no contexto da educação inclusiva}

O Referencial Curricular Nacional para a Educação Infantil (RECNEI), ao considerar o cuidado essencial e ao reconhecê-lo como um dos componentes da proposta curricular da Educação Infantil, estabelece diretrizes necessárias à construção de uma prática de atendimento cujo princípio é o de garantir as melhores oportunidades de desenvolvimento às crianças (BRASIL, 1998).

O RENEI define que a função das instituições de Educação infantil é a de educar e cuidar, constituindo-se como um dos núcleos essenciais ao convívio social de crianças (BRASIL,1998). Por isso, é pertinente considerar que as instituições de educação infantil possibilitam a observação e avaliação criteriosa do processo de interação da criança, sugerindo a elaboração de estratégias de intervenção nas áreas de desenvolvimento (imitação, percepção, coordenação motora fina, coordenação motora grossa, olho-mão, desempenho cognitivo e cognitivo verbal) e do comportamento (relacionamento e afeto, brincar e interesse por materiais, respostas sensoriais e linguagem). É oportuno salientar que devido ao tempo de permanência das crianças nas instituições de Educação infantil é necessário considerar que elas favorecem a identificação de déficits no desenvolvimento dessas crianças.

Frente a legislação brasileira e documentos normativos, crianças com diferentes idades e tipos de deficiências estão cada vez mais adentrando o espaço escolar em função das leis de inclusão. Em aspectos gerias, existem diversos marcos regulatórios que garantem o direito da inclusão, tais como: a Lei brasileira de Inclusão - 13.146/15, a Declaração de Salamanca (UNESCO, 1994), a Constituição Federal de 1988 (BRASIL, 1998), o Estatuto da Criança e do Adolescente, a Lei n. 8.069/90 (BRASIL, 1990), entre outros, que asseguram o direito das crianças gozarem de um sistema educacional inclusivo sem distinção de qualquer natureza. 
O Atendimento Educacional Especializado - AEE tem como função "identificar, elaborar e organizar recursos pedagógicos e de acessibilidade que eliminem as barreiras para a plena participação dos alunos, considerando suas necessidades específicas" sendo o atendimento uma complementação e/ou suplementação para a formação dos estudantes com vista à autonomia e independência dentro da escola e fora dela, Ministério da Educação (BRASIL, 2008).

Na perspectiva da Educação Inclusiva, a Política Nacional da Educação Especial na Perspectiva da Educação Inclusiva (BRASIL, 2008), garante que os alunos com diferentes tipos de deficiência, transtornos globais do desenvolvimento, altas habilidades/superdotação matriculados na classe comum da rede regular de ensino tenham seus direitos garantidos ao atendimento educacional especializado - AEE e na Sala de Recurso Multifuncional (SRM) de acordo com suas especificidades. A referida política ainda ressalta a necessidade do cumprimento de objetivos que assegurem o respeito ao ser humano, as suas singularidades e especificidades no âmbito escolar (BRASIL, 2008). Por esse motivo, a presente proposta requer dos professores a apropriação de conhecimentos específicos para avaliar crianças com TEA com o intuito de responder as necessidades educativas desses estudantes de forma responsável.

\section{METODOLOGIA}

Trata-se de uma pesquisa com foco na formação de professoras em uma perspectiva interdisciplinar (Educação/Saúde) com abordagem de pesquisa qualitativa. Segundo Tripp (2005) este tipo de pesquisa essencialmente envolve uma tentativa continuada e sistemática de aprimorar a prática pedagógica de professoras de creches públicas.

O foco da formação priorizou o uso dos instrumentos: Skill Growing Test que objetiva avaliar as Habilidades Crescentes, ou seja, nove áreas-chave: Postura Passiva, Postura ativa, Locomotor, Manipulativo, Visual, Audição e Linguagem, Fala e Linguagem, Social Interativo e Auto cuidado Social de crianças desde o nascimento até os 5 anos de idade; e o segundo instrumento foi o Perfil Psicoeducacional Revisado PEP-R (Psychoeducational Profile Revised-PPR), desenvolvido na Universidade da Carolina do Norte, em Chapel Hill, pelo Dr. Eric Schopler e sua equipe (SCHOPLER et al., 1990) utilizado para avaliação das escalas de desenvolvimento da criança com TEA/DI, ou seja, este instrumento tem a capacidade científica de avaliar 11 áreas, sendo 7 áreas do desenvolvimento e 4 áreas do domínio do comportamento, permitindo, dessa 
forma, identificar diferentes modelos de aprendizagem para uma idade cronológica que varia de seis meses a doze anos, devendo ser aplicado preferencialmente em crianças com idade pré-escolar. Esse instrumento permite identificar diferentes modelos de aprendizagem para uma idade cronológica que varia de seis meses a doze anos, devendo ser aplicado preferencialmente em crianças com idade pré-escolar.

O Kit para aplicação do PEP-R é composto por um conjunto de brinquedos e materiais pedagógicos que são apresentados à criança por um examinador que realiza as etapas de observação, avaliação e registro das respostas obtidas, com três possibilidades de registro: (i) passou, quando a tarefa é realizada com sucesso; (ii) reprovado quando há impossibilidade de realização da tarefa; (iii) emergente, quando a tarefa é realizada com sucesso. Dessa maneira, ao final da sessão, os escores da criança são distribuídos entre as sete áreas de desenvolvimento (imitação, percepção, coordenação motora fina, coordenação motora grossa, olho-mão, desempenho cognitivo e cognitivo verbal) composta por 131 itens, e as quatro áreas de comportamento (relacionamento e afeto, brincar e interesse por materiais, respostas sensoriais e linguagem), composta por 42 itens (SCHOPLER et al., 1990).

Devido ao contexto atual da Pandemia da COVID-19 foi utilizada para a realização das formações das professoras, a Plataforma Google meet como recurso tecnológico e de baixo custo. As formações seguiram a seguinte sequência:

- Treinamentos teórico abordando estudos da temática central e instrumentos avaliativos, constituindo-se a formação teórica necessária quanto a avaliação de acordo com a especificidade de cada instrumento.

- Foram disponibilizados Kits com material avaliativo e realizado encontros presenciais para esclarecimento de dúvidas.

- Foi aplicado um questionário avaliativo da formação com seis perguntas no modelo semiestruturado direcionada às professoras.

As perguntas do questionário foram elaboradas contendo como embasamento para sua formulação a literatura referente ao TEA e desenvolvimento infantil. Todas as informações adquiridas com o questionário resultaram na análise do olhar das professoras do AEE sob a influência da formação no contexto escolar de crianças com TEA e o novo cenário atual de uma pandemia no sentido da capacitação via meios tecnológicos, distintas possibilidades do uso dos instrumentos para contribuições e aprimoramento da avaliação 
dos domínios do desenvolvimento de crianças com TEA, além da formação continuada dessas professoras.

Sendo assim, foram organizadas da seguinte forma: Dados de identificação e aspectos específicos do atendimento aos alunos com TEA. "Por favor, escreva o nome da creche escola que você trabalha"; "Quantos alunos com TEA estão matriculados no Atendimento Educacional Especializado?", "Você já participou de alguma formação continuada com uso de instrumentos de avaliação para alunos com TEA?”, "O que você achou sobre a formação dos instrumentos Skill Growing Test e Perfil Psicoeducacional Revisado - PEP-R?”, “Como você avalia a formação com instrumentos estruturados usando a tecnologia das plataformas virtuais no contexto da pandemia?", "Como você avalia a sua atuação pedagógica durante este período da Pandemia Covid 19".

O referido questionário foi encaixado no cronograma previamente estabelecido, entretanto, para a continuidade da pesquisa relacionada a aplicação direta dos instrumentos de forma pratica com os alunos dependia, evidentemente da volta às aulas, o que, devido as medidas de distanciamento adotadas durante o período.

Participaram do estudo duas professoras atuantes no Atendimento Educacional Especializado (AEE) na Sala de Recurso Multifuncional (SRM) de duas creches públicas do município de São Luís - MA.

Os critérios de participação incluíam ser professor(a) do AEE, atender aluno com diagnóstico do Transtorno do Espectro Autista - TEA e aceitar participar da pesquisa. Os critérios de exclusão incluíram ser professor(a) do AEE e no período da pesquisa estar afastada das suas atividades ou de licença por quaisquer motivos.

Todos os participantes assinaram o Termo de Consentimento Livre e Esclarecido (TCLE). A pesquisa foi autorizada pela Secretaria Municipal de Educação do Município de São Luís - MA e aprovado pelo Comitê de Ética e Pesquisa (CEP) da Universidade Federal do Maranhão - UFMA, sob o CAAE: 97016718.2.0000.5087, conforme determina a Resolução do Conselho Nacional de Saúde $n^{\circ}$ 510/16 CNS/MS e suas complementares para pesquisas envolvendo seres humanos. Recebeu incentivos da Fundação de Amparo à Pesquisa e ao Desenvolvimento Científico e Tecnológico do Maranhão - FAPEMA para subsidiar despesas necessárias à execução do Projeto e compra dos instrumentos usados na formação das professoras do AEE. 


\section{RESULTADOS E DISCUSSÃO}

O processo de formação das professoras contou com nove encontros mistos, online e presencial. Inicialmente com a equipe de pesquisadores foi realizado as primeiras aproximações com as professoras por meio de uma reunião presencial com apresentação de alguns integrantes dessa equipe, sendo pesquisadores de iniciação científica, a coordenadora e a vice-coordenadora, todos respeitando as medidas preventivas de distanciamento social e seguindo os protocolos estabelecidos pela Organização Mundial da Saúde (OMS) e Ministério da Saúde (MS).

$\mathrm{Na}$ primeira reunião foram apresentados os objetivos da pesquisa, os instrumentos e assinatura do termo de consentimento livre e esclarecido (TCLE).

As reuniões e formações aconteceram consecutivamente em dias e horários agendados previamente de acordo com a disponibilidade das professoras e formadora.

Em relação a entrevista, os formulários foram enviados de forma online, cada professora respondeu no seu tempo e retornaram em um prazo de três dias.

\section{O Processo de intervenção}

Cabe aqui ressaltar que durante o processo de intervenção aconteceram encontros presenciais em uma das creches, especificamente na creche Maria de Jesus Carvalho (SEMED) a qual responde pela educação de estudantes da Educação Infantil em São Luís, sendo o primeiro, dia 19/02/2021 para apresentação da pesquisa e uma breve apresentação dos instrumentos, dialogando acerca do TEA no contexto da creche pública, seus desafios, dificuldades, e perspectivas da aprendizagem e desenvolvimento educacional em meio uma pandemia, também foram assinados os Termos de Consentimento Livre e Esclarecido - TCLE, esses dados podem ser conferidos no Quadro 1 , conforme segue.

Quadro 1 - Encontros cronológico do período de execução da intervenção

\begin{tabular}{|c|l|l|}
\hline $\begin{array}{c}\text { FORMAÇÃO E } \\
\text { ATIVIDADES }\end{array}$ & \multicolumn{1}{|c|}{ DATAS } & \multicolumn{1}{c|}{ LOCAL } \\
\hline Apresentação & 19 de fevereiro & $\begin{array}{l}\text { Presencial: creche } \\
\text { Maria de Jesus carvalho }\end{array}$ \\
\hline Formação & 26 de março & Sala virtual Meet \\
\hline
\end{tabular}




\begin{tabular}{|c|c|c|}
\hline \multirow[t]{2}{*}{ Schedule of Growing Skills II } & 19 de maio de 2021 & Sala virtual Meet \\
\hline & 23 de maio de 2021 & Sala virtual Meet \\
\hline \multirow{3}{*}{$\begin{array}{c}\text { Formação } \\
\text { Escala de Habilidades e Perfil } \\
\text { Psicoeducacional Revisado } \\
\text { PEP-R }\end{array}$} & 08 de abril & Sala virtual Meet \\
\hline & 11 de maio 2021 & Sala virtual Meet \\
\hline & 19 de maio 2021 & Sala virtual Meet \\
\hline $\begin{array}{c}\text { Entrega dos kits formativos } \\
\text { (Material teórico e } \\
\text { instrumentos) }\end{array}$ & 21 de maio de 2021 & $\begin{array}{l}\text { Presencial: creche } \\
\text { Maria de Jesus carvalho }\end{array}$ \\
\hline $\begin{array}{l}\text { Reunião com professoras e o } \\
\text { superintendente da SEMED }\end{array}$ & 02 de junho de 2021 & $\begin{array}{l}\text { Presencial: creche } \\
\text { Maria de Jesus carvalho }\end{array}$ \\
\hline Aplicação do questionário & 07 de julho de 2021 & Google formulário \\
\hline
\end{tabular}

Fonte: Elaborado pelas Autoras (2022)

\section{Apresentação dos Dados da Entrevista}

Professora 1, creche A:

A professora 1 conta com 5 alunos autistas na educação infantil na creche A, afirma já ter participado de formações especificas para alunos com transtorno do aspecto autista, estas formações realizadas durante sua trajetória profissional foram oferecidas pela rede municipal de educação do município de São Luís - MA. Em relação a formação com os dois instrumentos de avaliação, o Skill Growing Test e Escala de Habilidades e o Perfil Psicoeducacional PEP-R, sentiu-se instigada a aprender mais e progredir para maior aperfeiçoamento e uso desses com seus alunos.

A professora detalha que tais conhecimentos sobre os itens e áreas da Escala de Comportamento e da Escala de Desenvolvimento são de caráter essencial para o atendimento especializado na sala de recurso com os alunos e também com os pais. Quanto a avaliação da intervenção realizada como ferramenta de apoio a tecnologia das plataformas virtuais (Google Meet), a professora frisou que as ferramentas tecnológicas devem viabilizar o desenvolvimento desse processo, fomentando a capacitação e o conhecimento das plataformas online e das novas formas de avaliação do desenvolvimento das crianças independente da paralização dos encontros presenciais, toda via, tal professora aponta, ainda, certa dificuldade com a adaptação dessas 
plataformas digitais, contudo, ressaltou que se esses softwares forem usados de modo contextualizado podem aproximar o virtual daquilo vivido na vida real.

Quanto a questão da atuação pedagógica no contexto da pandemia Covid - 19, a professora 1 se auto avalia com uma boa atuação na missão de educar, apresentando, no entanto, um pouco de entraves, pois trabalha com uma comunidade de realidades diferentes (Baixo nível sócio econômico) onde tal adversidade acaba interrompendo o trabalho pedagógico e a deixando sem muita perspectiva de uma qualidade de aprendizado satisfatório dos seus alunos.

Professora 2, creche B:

A referida professora trabalha com 18 alunos diagnosticados com TEA matriculados no Atendimento Educacional Especializado na educação infantil da escola B, afirma ter participado de formação continuada durante sua atuação profissional e pedagógica para alunos com autismo. Sobre sua consideração acerca da formação dos instrumentos Skill Growing Test e Perfil Psicoeducacional Revisado - PEP-R apreciou como muito interessante e de grande valia, pois a possibilita um leque maior no entendimento e processo de ação das atividades promotoras do desenvolvimento do aluno com TEA nos primeiros anos de vida, percebendo com os dois instrumentos que existem diferentes áreas do desenvolvimento da criança que podem ser exploradas, conseguindo um panorama do aluno no momento da aplicação do teste.

A professor relatou que durante o processo de intervenção foi possível compreender por meio das fichas de avaliação que existe áreas e comportamentos do aluno autista que não sabia que podiam ser avaliadas, evidenciando grande proporção do poder das escala avaliativa dos dois instrumentos. Dessa maneira, quando questionada sobre o uso da tecnologia das plataformas virtuais para a intervenção no contexto do distanciamento social, avaliou de forma muito positiva pois com a videoconferência houve maior flexibilidade para as aulas na dinâmica do processo de formação sem precisar sair de casa e sem risco de contaminação por covid além de poder marcar horário viável após as demandas profissionais e pessoais pois além de ser professora também é mãe.

No que se refere a atuação pedagógica como professora do AEE durante no contexto da Pandemia Covid - 19, a professora relatou fazer o possível para desenvolver um bom trabalho mesmo com isolamento social e quarentena rígida no município de São Luís - MA, esta professora avaliou-se positivamente, apesar dos entraves encontrados 
nesse período de grande impacto social, tornando para os educadores uma época desafiadora para processo de educação.

\section{Principais Achados}

A avaliação dos resultados da intervenção com Skill Growing Test e Perfil Psicoeducacional Revisado - PEP-R apontaram evidencias científicas para alavancar a formação de professoras do Atendimento Educacional Especializado - AEE atuantes no trabalho com crianças diagnosticadas com autismo em creches de domínio público no município de São Luís-MA.

Foi possível compreender que as professoras carecem de maior aperfeiçoamento em relação a avaliação das habilidades crescentes e diferentes áreas do desenvolvimento infantil das crianças atendidas no $\mathrm{AEE}$, ou seja, foi evidenciado que, nas duas creches não se base com instrumentos para avaliar as potencialidades ou os déficits do aluno com deficiência para intervenção pedagógica.

Um dado instigante, tanto para o município, o Maranhão quanto próprio Estado brasileiro, visto existir evidencias de que a atuação precoce na infância auxilia no melhor desenvolvimento da criança autista (ZAQUEU et al., 2015; ZAQUEU, 2010). Contudo, é percebido total escassez de instrumentos de avaliação principalmente em português dificultando seu uso nas escola e as próprias políticas afirmativas nesta área.

Os resultados da percepção das professoras permitiram perceber que, dada a diferença do número de alunos com TEA atendidos em cada creche escola, algumas variáveis se repetem, como preocupações com a realidade do ambiente que os alunos vivem, condição socio econômica das famílias e o fiel interesse em se aperfeiçoar com treinamento específicos que possam nortear a avaliação das habilidades de alunos nos primeiros cinco anos de vida e que as habilitem na aplicação do teste e interpretação dos dados.

A partir da fala das professoras entrevistadas, constatou-se que as diferentes tecnologias e plataformas digitais de vídeo conferencia como, o Google Meet utilizado nesta investigação contribuiu efetivamente com a formação em um contexto de extremo distanciamento social brasileiro e paralização de todo e qualquer movimento das creches públicas no município de São Luís. Neste aspecto, vale ressaltar que o atual cenário ocasionado pela Pandemia da COVID 19, gerou muitos ajustes em relação à pesquisa e suspensão das atividades presenciais, entretanto, mesmo diante desta situação, as 
professoras demonstraram interesse na formação dos instrumentos para melhor planejar intervenções psicoeducacionais para os seus alunos.

As professoras demostraram um alinhamento de ideias em relação a funcionalidade dos instrumentos como possível potencializador da sua atuação com alunos com TEA, compreendendo que, além de auxiliar na avaliação do desenvolvimento de forma criteriosa, possibilitou a compreensão de cada área avaliada em relação ao desenvolvimento das crianças por meio do instrumento Skill Growing Test: Postura Passiva, Postura ativa, Locomotor, Manipulativo, Visual, Audição e Linguagem, Fala e Linguagem, Social Interativo e Auto cuidado Social.

E importante considerar que a avaliação do desenvolvimento de crianças com TEA por meio do Perfil Psicoeducacional Revisado - PEP-R possilita a compreensão das áreas avaliadas para nortear intervenções específicas direcionadas às necessidades dessas crianças. Assim, vale destacar uma dissertação de mestrado que utilizou este instrumento para avaliar crianças com TEA no contexto de creches públicas com o intuito de investigar a competência social com o intuito de elaborar um Caderno de Orientações (CompeTEA) para professores atuantes na educação infantil (LEITE, 2019). Este citado estudo conclui que a avaliação pedagógica é necessária, assim como o material pedagógico e uma intervenção específica para favorecer a Competência Social em crianças com TEA baseados em intervenções psicoeducacionais, e que a formação de professores não deve ser negligenciada.

A formação para avaliar o desenvolvimento infantil vem contribuir e nortear a implantação de intervenções psicopedagógicas nas áreas apontadas pelos instrumentos nas quais as crianças demandam maior atenção. Assim, os resultados ainda corroboram com a aquisição pelos professores de fundamentação teórica para atuar com crianças com TEA e oferecer sugestões aos pais para interagir com o seus filhos no ambiente doméstico, ampliando as possibilidades das intervenções que são realizadas nas atividades exercidas no atendimento educacional especializado da escola, indo de acordo com a Lei de Diretrizes e Bases 9.394/96, cap. III, art $2^{\circ}$ incluindo a família no dever do pleno desenvolvimento do educando, nesse cenário as educadoras corroboram para que os pais consigam os subsídios educacional para seus filhos (BRASIL, 1996).

De modo geral, as professoras pontuaram uma percepção positiva do seu engajamento pedagógico no cenário da Pandemia COVID-19, ressaltando que para seus alunos com transtorno do espectro autista, demonstraram a preocupação com os "entraves" acerca das dificuldades das famílias para acompanhar o desenvolvimento das 
crianças com TEA. Estas questões podem estar relacionadas a baixa condição socioeconômica das famílias das crianças com TEA atendidas nas instituições de educação infantil participantes da pesquisa, gerando com isso prováveis impactos na qualidade de vida das crianças com TEA e de suas famílias.

\section{CONSIDERAÇÕES FINAIS}

A pesquisa se configura como uma das primeiras no município de São Luís do Maranhão a realizar formação de professoras para avaliar e, consequentemente intervir com crianças com TEA direcionadas às professoras do atendimento educacional especializado em creches de São Luís no cenário de uma pandemia COVID 19. Este estudo trouxe à tona reflexões acerca das necessidades de formação continuada para as professoras do Atendimento Educacional Especializado (AEE) na Sala de Recurso Multifuncional (SRM) atuantes com crianças com TEA. Neste aspecto, oportunizou a formação abrangente dessas professoras na perspectiva da avaliação com instrumentos de reconhecidos e criteriosos para compreender o desenvolvimento infantil por meio de plataformas online, como o google meet.

Frente aos resultados encontrados, este estudo se configura como um desafio visto a paralização das atividades planejadas ocasianadas pela Pandemia da COVID 19 e a retomada das atividades escolares baseadas em novas estratégias de ensino envolvendo formatos digitais no comprimento do cronograma estabelecido. Neste sentido, esse estudo envolveu duas instituições que se articularam para produzir conhecimentos específicos em um cenário de distanciamento social, fruto de uma parceria entre a Universidade Federal do Maranhão-UFMA e a Secretaria Municial de Educação de São Luís/MASEMED.

De modo geral, o estudo amplia algumas possibilidades tais como, a formação das professoras em um contexto interdisciplinar (educação/saúde para educação especial e inclusiva), fornecendo meios que vão para além das duas escolas/creches participantes da pesquisa, mas suscitando possibilidades que poderão expandir para outros os profissionais das redes de ensino municipal, estadual, pública ou privada que apresentarem, por conseguinte, objetivos que venham ao encontro da educação especial e inclusiva.

E por fim, é oportuno frisar que no cenário brasileiro e maranhaense, a Educação 
de estudantes com TEA tem sido garantida nos documentos normativos nacionais, conforme a legislação específica foi apresentada neste artigo, entretanto, constatamos que as ações educacionais direcionadas a este público alvo ainda precisam tornar-se mais equalizadas regionalmente no Brasil para proporcionar intervenções mais específicas a esses estudantes com base em boas evidências científicas. Assim, consideramos necessário ampliar estudos no contexto de creches no município de São Luís que possam produzir boas evidências sobre a formação necessária aos professores para avaliar e intervir com crianças com TEA, ampliando a compreensão das especificidades de outras crianças público-alvo da educação especial e inclusiva priorizando as principais necessidades de suas famílias.

\section{REFERÊNCIAS}

American Psychiatric Association - APA.Diagnostic and statistical manual of mental disorders (5a ed.). Washington, DC: APA. 2014.

BRASIL. Constituição da republica Federativa. Brasília: Senado Federal. 1988.

BRASIL. Lei de Diretrizes e Bases da Educação Nacional: lei no 9.394, de 20 de dezembro de 1996, que estabelece as diretrizes e bases da educação nacional. 5. Ed. Brasilia: Câmara dos Deputados, coordenação Edições Câmara, 2010. Disponível em: http://bd.camara.gov.br/bd/bitstream/handle/bdcamara/2762/ldb_5ed.pdf. Acesso em: $03 / 02 / 2021$

BRASIL. Estatuto da Criança e do Adolescente: Lei no 8.069, de 13 de julho de 1990, atualizado com a Lei 12.010 de 2009. Inclusa a Lei ${ }^{\circ} 12.594$ de 2012 (SINASE). Disponivel em:

http://www.tjsc.jus.br/infjuv/documentos/ECA_CEIJ/Estatuto\%20da\%20Crian\%C3\%A 7a\%20e\%20do\%20Adolescente\%20editado\%20pela\%20CEIJ-

SC\%20vers\%C3\%A3o\%20digital.pdf. Acesso em 28/09/2020

BRASIL. Ministério da Educação. Referencial Curricular Nacional para a Educação Infantil. Brasília. MEC/SEF. 1998.

BRASIL. Ministério da Educação e Cultura. Política Nacional de Educação Especial na Perspectiva da Educação Inclusiva. Documento elaborado pela Portaria Ministerial $n^{\circ} 555$, de 5 de junho de 2007, prorrogada pela Portaria $n^{\circ} 948$ de 09 de outubro de 2007.Disponível em: http//portal.mec.gov.br/seesp/arquivos/pdf/politica.pdf. Acesso em 28/09/2020.

BRASIL. Lei $\mathbf{n}^{\mathbf{0}}$ 12.764, de 27 de dezembro de 2012. Institui a Política Nacional de Proteção dos Direitos da Pessoa com Transtorno do Espectro Autista; e altera o $\S 3^{\circ}$ do art. 98 da Lei ${ }^{\circ}$ 8.112, de 11 de dezembro de 1990. Brasília, DF: Diário Oficial da União, 2012. Disponível em http://www.planalto.gov.br/ccivil_03/_ato20112014/2012/lei/112764.htm. Acesso em: 23 nov. 2020. 
BRASIL.Lei Brasileira de Inclusão da Pessoa com Deficiência (Estatuto da Pessoa com Deficiência) $\mathrm{n}^{\circ}$ 13.146, de 06 de julho de 2015. Disponível em:

http://www.planalto.gov.br/ccivil_03/_ato2015-2018/2015/Lei/L13146.htm. Acesso em: 11 mar. 2021.

FIGUEIRAS, Amira Consuelo, SOUZA, Isabel Cristina Neves de; RIOS, Viviana Graziela; BENGUIGUI, Yehuda. OPAS. Organização Pan-americana de Saúde. Manual de vigilância do desenvolvimento infantil no contexto da AIDPI. Washington, D.C.: OPS, 2005.

LEITE, Emanuelle Santiago Monteiro. COMPETÊNCIA SOCIAL EM PRÉESCOLARES COM TRANSTORNO DO ESPECTRO AUTISTA: um estudo de intervenção no município de Santa Inês - MA. Dissertação (Mestrado) - Programa de Pós-graduação em Gestão de Ensino da Educação Básica, Universidade Federal do Maranhão, São Luís, p. 170. 2019.

SAULNIER, C., QUIEMBACH, L. E., KLIN, A. Avaliação Clínica De Crianças Com Transtornos do Espectro do Autismo. In J. S. Schwartzman; C. A. Araujo (Eds.),

Transtornos do Espectro do Autismo. p. 159-172. São Paulo: Memnon. 2011.

SCHOPLER, E.; LANSING, M. D.; REICHLER, R. J.; MARCUS, L. M.

Psychoeducational Profile: TEACCH individualized assessment for children with autism spectrum disorders. 3 ed. Austin, TX: Pro-Ed, Inc. 2005.

TRIPP, D. Pesquisa-ação: uma introdução metodológica. Educação e Pesquisa, São Paulo, v. 31, n. 3, p. 443-466, 2005.

ZAQUEU, L. C. C.; TEIXEIRA, M. C. T. V.; ALCKMIN-CARVALHO, F. A.; PAULA, C. S. Associações entre Sinais Precoces de Autismo, Atenção Compartilhada e Atrasos no Desenvolvimento Infantil. Psicologia: Teoria e Pesquisa (Brasília. Online), v.31, p.293 - 302, 2015.

ZAQUEU, L. C. C.; TEIXEIRA, M. C. T. V.; CARVALHO, F. A.; D'ANTINO, M. E. F. ; PAULA, C. S. Prejuízos nos comportamentos de atenção compartilhada associados a sinais precoces de Transtornos do Espectro do Autismo In: Contribuições para a inclusão escolar de alunos com necessidades especiais: Estudos interdisciplinares em educação e saúde em alunos com Transtorno do Espectro do Autismo no município de Barueri/SP. Ed.São Paulo: Memnon, 2015, v.2, p. 58-67.

UNESCO. Declaração de Salamanca. Sobre Princípios, Políticas e Práticas na Área das Necessidades Educativas Especiais, 1994. UNESCO. Disponível em:

http://unesdoc.unesco.org/images/0013/001393/139394por.pdf. Acesso em: 04/03/2021.

Recebido em: 20/01/2022

Aprovado em: 21/02/2022

Publicado em: 24/02/2022 